\title{
RELAÇÕES ENTRE CIÊNCIA, TECNOLOGIA E SOCIEDADE EM UMA OFICINA TEMÁTICA SOBRE ADITIVOS ALIMENTARES
}

\author{
Science, Technology and Society Relations an a Workshop on Food Additives
}

\author{
Naiade Regina Pinto* \\ Tathiane Milaré***
}

\begin{abstract}
Resumo: Os objetivos deste artigo são investigar o desenvolvimento e as contribuições de uma oficina temática para a abordagem contextualizada de conhecimentos científicos e das relações CTS, bem como discutir alguns indicadores do ensino de ciências para a cidadania. Para isso, uma oficina temática sobre aditivos alimentares foi elaborada e realizada no contexto de um projeto de extensão universitária. Como resultados, verificou-se que as oficinas podem ser uma estratégia eficaz para promover estudos sobre a ciência de forma interligada à tecnologia e à sociedade, contribuindo para a divulgação científica e para a formação docente. Além disso, são apontadas algumas estratégias que favorecem a participação, reflexão e discussão, ações necessárias para a educação científica.
\end{abstract}

Palavras-chave: Extensão. Formação docente. Ensino de química.

\begin{abstract}
The aim of this paper is to investigate the development and contributions of a thematic workshop to the contextualized approach of scientific knowledge and science, technology and society relations, as well as, to discuss some indicators of science teaching for citizenship. For this, a thematic workshop on food additives was created and developed in the context of a university extension project. As a result, it was found that workshops can be an effective strategy to promote studies on science interconnecting technology and society, contributing to scientific dissemination and teacher training. In addition, there are some strategies that favor participation, reflexion and discussion, necessary actions for scientific education.
\end{abstract}

Keywords: Extension. Teacher education. Chemical education.

\section{Introdução}

Oficinas temáticas têm sido utilizadas como uma proposta metodológica com diversas contribuições para os processos de ensino e aprendizagem e de formação da cidadania, uma vez

\footnotetext{
* Licenciada em Química pela Universidade Federal de São Carlos (UFSCar). Assistente de Laboratório de Pesquisa e Desenvolvimento de Aromas na Empresa Carlos Cramer Produtos Aromáticos do Brasil. Orcid iD: 0000-0002-3492-5250. E-mail: naiade6@hotmail.com.

** Licenciada em Química pelo Instituto de Química de Araraquara (IQ/Unesp), mestre em Educação Científica e Tecnológica pela Universidade Federal de Santa Catarina (UFSC) e doutora em Ensino de Ciências pela Universidade de São Paulo (USP). Professora adjunta do Departamento de Ciências da Natureza, Matemática e Educação da Universidade Federal de São Carlos (UFSCar), campus Araras. Orcid iD: https://orcid.org/00000001-6557-1769. E-mail: tmilare@ufscar.br.
} 
que possibilitam a contextualização, problematização e a experimentação baseada na abordagem temática e, por meio dessas estratégias, estimulam o posicionamento ativo e crítico na sociedade. Também permitem problematizar temas presentes no cotidiano, possibilitando o estudo da realidade com respaldo científico, conduzindo o indivíduo a relacionar o tema com a ciência e a reconhecer a importância dos conhecimentos científicos para si próprio e para a comunidade a qual pertence (MARCONDES, 2008).

Por abrangerem estratégias didáticas adaptáveis ao tema, ao tempo e ao público, conforme seus objetivos de aprendizagem, as oficinas também contribuem significativamente para a divulgação científica, bem como para um envolvimento participativo e descontraído, podendo ser realizadas em espaços não escolares. Quando elaboradas sem restrições para a participação, o público em geral apresenta interesse de acordo com seu propósito pessoal ou curiosidade. Em função desses aspectos, as oficinas temáticas estão sendo cada vez mais utilizadas no ensino de ciências (OLIVEIRA et al., 2012; SOUZA et al., 2014; SILVA et al., 2014; GARCÊS, 2016; DIAS, 2016; PISTARINI, MILARÉ, 2019).

Esse contexto parece potente também para se pensar em propostas que contemplem as relações Ciência, Tecnologia e Sociedade (CTS) fora da sala de aula por meio do desenvolvimento de oficinas em torno de temas sociocientíficos. A abordagem CTS propõe o ensino contextualizado em que o tripé Ciência, Tecnologia e Sociedade é explorado por meio do estudo de suas inter-relações, ou seja, da interdependência entre seus componentes, centrado na organização conceitual em temas sociais, desenvolvimento de juízo crítico e por uma concepção de ciência voltada para o interesse social, ou seja, propõe a compreensão das implicações sociais relacionadas ao conhecimento científico (SANTOS; SCHNETZLER, 2010). Segundo Santos (2002), a introdução de temas sociocientíficos vem sendo largamente usada em abordagens CTS, em que os conteúdos científicos se articulam em torno de temas científicos ou tecnológicos que são potencialmente problemáticos do ponto de vista social, de modo a desenvolver a argumentação na formação para a cidadania.

Levando em consideração que o exercício da cidadania está diretamente relacionado com a atuação nas diferentes esferas da sociedade, compreende-se que para uma participação cidadã ativa é preciso que os indivíduos estejam em contato com informações vinculadas a problemas sociais, políticos, econômicos, ambientais etc., os quais exigem reflexão, participação e posicionamento frente às decisões e soluções. Nesse sentido, considera-se que essas informações incluem necessariamente assuntos que estão diretamente relacionados à ciência e, por isso, é de suma importância que os indivíduos tenham uma educação que propicie o envolvimento em questões deste cunho, o qual deve ser próximo e significativo (SANTOS; SCHNETZLER, 2010).

É nesse sentido que este trabalho visa contribuir, buscando respostas para questões como: de que forma oficinas temáticas com abordagem CTS podem ser desenvolvidas? Quais são as contribuições dessas oficinas para a formação dos participantes? Quais as potencialidades e limitações das oficinas em torno de temas sociocientíficos em espaços não escolares? Os objetivos são investigar o desenvolvimento e as contribuições de uma oficina temática para a abordagem contextualizada de conhecimentos científicos e das relações CTS e discutir alguns indicadores do ensino de ciências para a cidadania.

A oficina investigada foi realizada no contexto de um projeto de extensão que tem como objetivos elaborar e oferecer à comunidade em geral oficinas com temas que relacionem conhecimentos químicos com a cidadania como, por exemplo, reciclagem, consumismo, cosméticos, drogas, automedicação e alimentação. O projeto conta com a participação de estudantes do curso de licenciatura em química na criação, regência e avaliação dessas oficinas, 

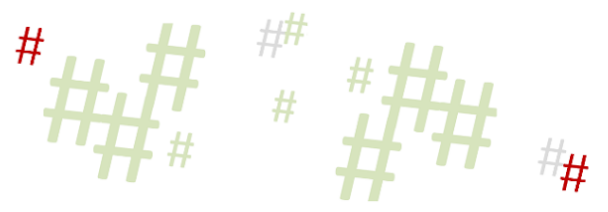

articulando ensino, pesquisa e extensão no contexto da formação inicial de professores. $\mathrm{O}$ projeto permite que os licenciandos participantes reflitam sobre a prática docente e trabalhem no desenvolvimento de novas metodologias, explorando os conhecimentos aprendidos no decorrer da graduação.

\section{Abordagem CTS e temas sociocientíficos}

A educação, de forma geral, tem responsabilidade na formação das pessoas para o exercício de uma postura ativa em vida social, de modo comprometido com uma sociedade democrática, justa, segura e sustentável. Desse modo, pensar no papel da educação implica entender dois aspectos: a formação cidadã e a participação ativa. Cunha (2008) pontua que a formação cidadã está basicamente direcionada ao desenvolvimento da capacidade de tomada de decisões. Assim, de acordo com esse mesmo autor "um cidadão deve estar apto a tomar decisões conscientes sobre os assuntos que permeiam a comunidade em que vive bem como toda a sociedade, sejam eles de caráter econômico, político, científico ou cultural" (CUNHA, 2008, p. 18). Santos e Schnetzler (2010) sintetizam que educar para a cidadania é preparar o indivíduo para a participação ativa, ou seja, prepará-lo para participar e se posicionar em uma sociedade democrática, por meio da garantia de seus direitos e do compromisso de seus deveres.

Desse modo, percebe-se que a formação cidadã está diretamente relacionada ao desenvolvimento da participação ativa. São aspectos a serem considerados de forma conjunta e que, essencialmente, envolvem atitudes de tomada de decisões, participação e posicionamento crítico. Para que o cidadão exerça uma participação ativa em vida social é preciso que ele esteja em contato com uma gama de informações que afetam a vida em sociedade para, então, exercer um posicionamento e buscar soluções frente às diversas situações e problemas. Dentre esta gama de informações, o domínio de conhecimentos que envolvem a ciência e a tecnologia é imprescindível, dada a grande influência que essas áreas de conhecimento exercem no mundo todo (CUNHA, 2008; SANTOS; SCHNETZLER, 2010).

É possível observar que a sociedade moderna estabeleceu uma grande dependência com relação às criações advindas do desenvolvimento científico e tecnológico, de modo que a vida em sociedade está vinculada a incontáveis produtos e situações que são frutos desse desenvolvimento, que vão desde o uso diário de produtos químicos até a repercussão na produção de alimentos, geração de energia, inovações na medicina e efeitos ambientais, por exemplo. É fundamental que os indivíduos tenham contato com conhecimentos relacionados ao emprego da ciência e que compreendam as implicações científico-tecnológicas na sociedade, em seus aspectos benéficos e maléficos, os quais estão vinculados não somente a avanços, como também ao surgimento e ao agravamento de inúmeros problemas que se estendem a consequências políticas, econômicas, ambientais e sociais, para que então, assumam um posicionamento diante as inúmeras influências e impactos de suas aplicações (SANTOS; SCHNETZLER, 2010). Nesse contexto, a Indústria Química merece destaque, pois se apresenta como um dos setores mais dependentes dos avanços científico-tecnológicos que exercem influência direta na vida em sociedade.

Os conhecimentos químicos, dentre os conhecimentos da área da ciência, são de suma importância e não podem se resumir a um ensino neutro, sem compromisso com a sociedade, apolítico e descontextualizado (TEIXEIRA, 2011). Entretanto, frequentemente, o ensino de ciências ainda é caracterizado pelo conteudismo exacerbado, memorização sem compreensão, falta de contextualização, conteúdos fragmentados, ausência de interdisciplinaridade etc. Além disso, remete a uma educação que se desenvolve de maneira a não considerar os conhecimentos prévios dos estudantes, aspectos históricos e questões sociais, configurando, portanto, um 
ensino que não garante a compreensão de assuntos no âmbito da ciência e tampouco contribui para a formação do cidadão (TEIXEIRA, 2011).

Diante desse quadro, ressalta-se a necessidade de um ensino significativo e contextualizado, voltado para a compreensão dos conceitos e fenômenos, que proporcione condições para o desenvolvimento da tomada de decisões bem como de uma postura ativa, crítica e consciente. Reconhece-se a importância de contribuir para uma educação comprometida com a formação científica do cidadão, que permita sua participação ativa na vida em sociedade e que possibilite entender e reconhecer as implicações da ciência para si e para todos e, partindo disso, a importância das investigações e do desenvolvimento de estratégias que venham a colaborar com estes objetivos.

Nesta linha de raciocínio é que a abordagem CTS ganha destaque, correspondendo ao estudo das inter-relações existentes entre a ciência, a tecnologia e a sociedade, constituindo um campo de trabalho que se volta tanto para a investigação acadêmica como para as políticas públicas (PINHEIRO, 2005). A abordagem CTS busca entender os aspectos sociais do desenvolvimento científico e tecnológico, tanto os benefícios que esse desenvolvimento pode trazer, como também as consequências sociais e ambientais que poderá causar. A autora ainda pontua que, desde o início do movimento CTS, um dos principais campos de sua investigação tem sido o setor da educação e sinaliza a necessidade de renovação na estrutura curricular dos conteúdos, de forma a colocar a ciência e a tecnologia em novas concepções vinculadas ao contexto social.

Santos e Mortimer (2000) caracterizam a abordagem CTS pela integração do conhecimento científico com a tecnologia e o mundo social de experiências do dia a dia, relacionando a educação científica, tecnológica e social, de modo que os conteúdos científicos e tecnológicos são estudados juntamente com a discussão de seus aspectos históricos, éticos, políticos e socioeconômicos. Bybee (1987, apud SANTOS; MORTIMER, 2000) caracteriza a orientação curricular CTS como pesquisa e desenvolvimento de currículos que contemplem, entre outros, a apresentação de conhecimentos e habilidades científicos e tecnológicos em um contexto pessoal e social; a inclusão de conhecimentos e habilidades tecnológicos; a ampliação dos processos de investigação de modo a incluir a tomada de decisão e a implementação de projetos de CTS no sistema escolar.

De acordo com Aikenhead (1990, apud SANTOS; SCHNETZLER, 2010), a abordagem CTS pode ser resumida nos seguintes aspectos: interação entre ciência, tecnologia e sociedade; processos tecnológicos; temas sociais relativos à ciência e tecnologia; aspectos filosóficos e históricos da ciência; aspectos sociais de interesse da comunidade científica e a inter-relação entre os aspectos enumerados. Além disso, ainda em relação à caracterização desta abordagem, Santos e Schnetzler (2010) discorrem em um capítulo de seu livro sobre os aspectos que devem ser contemplados em uma abordagem CTS, os quais são destacados no Quadro 1. 
Quadro 1 - Nove aspectos da abordagem de CTS.

\begin{tabular}{|c|c|}
\hline Aspetos de CTS & $\begin{array}{l}\text { Esclarecimentos } \\
\end{array}$ \\
\hline Natureza da Ciência & $\begin{array}{l}\text { Ciência é uma busca de conhecimentos dentro de uma perspectiva } \\
\text { social. }\end{array}$ \\
\hline Natureza da Tecnologia & $\begin{array}{l}\text { Tecnologia envolve o uso do conhecimento científico e de outros } \\
\text { conhecimentos para resolver problemas práticos. A humanidade } \\
\text { sempre teve tecnologia. }\end{array}$ \\
\hline Natureza da Sociedade & $\begin{array}{l}\text { A sociedade é uma instituição humana na qual ocorrem mudanças } \\
\text { científicas tecnológicas. }\end{array}$ \\
\hline $\begin{array}{l}\text { Efeito da Ciência sobre a } \\
\text { Tecnologia } \\
\end{array}$ & $\begin{array}{c}\text { A produção de novos conhecimentos tem estimulado mudanças } \\
\text { tecnológicas. }\end{array}$ \\
\hline $\begin{array}{l}\text { Efeitos da Tecnologia sobre a } \\
\text { Sociedade }\end{array}$ & $\begin{array}{l}\text { A tecnologia disponível a um grupo humano influencia grandemente } \\
\text { o estilo de vida do grupo. }\end{array}$ \\
\hline $\begin{array}{l}\text { Efeito da Sociedade sobre a } \\
\text { Ciência }\end{array}$ & $\begin{array}{l}\text { Através de investimentos e outras pressões, a sociedade influencia a } \\
\text { direção da pesquisa científica. }\end{array}$ \\
\hline $\begin{array}{l}\text { Efeito da Ciência sobre a } \\
\text { Sociedade }\end{array}$ & $\begin{array}{c}\text { O desenvolvimento de teorias científicas podem influenciar o } \\
\text { pensamento das pessoas e as soluções de problemas. }\end{array}$ \\
\hline $\begin{array}{l}\text { Efeito da Sociedade sobre a } \\
\text { Tecnologia }\end{array}$ & $\begin{array}{c}\text { Pressões dos órgãos públicos e de empresas privadas podem } \\
\text { influenciar a direção da solução do problema e, em consequências, } \\
\text { promover mudanças tecnológicas. }\end{array}$ \\
\hline $\begin{array}{l}\text { Efeito da Tecnologia sobre } \\
\text { Ciência }\end{array}$ & $\begin{array}{c}\text { A disponibilidade dos recursos tecnológicos limitará ou ampliará os } \\
\text { progressos científicos. }\end{array}$ \\
\hline
\end{tabular}

Fonte: Mckavanag e Maher apud Santos e Schnetzler, 2010, p. 69.

Teixeira (2011, p. 99) destaca as seguintes proposições em relação à abordagem CTS:

a) a preocupação em termos dos objetivos da educação científica, colocada num sentido mais amplo e em sintonia com os demais componentes curriculares, concorrendo para uma visão de educação básica voltada para formação da cidadania;

b) a visão crítica sobre a natureza da ciência e seu papel na sociedade capitalista;

c) a focalização da programação em torno de temas sociais e não somente nos conceitos científicos fechados em si mesmos (que possuem valor em si mesmo);

d) a grande preocupação com estratégias de ensino que efetivamente promovam a interdisciplinaridade e a contextualização;

e) as recomendações para a utilização de uma multiplicidade de técnicas de ensino e estratégias didáticas sempre destinadas a levar os educandos ao mergulho nas questões sociais de relevância e interesse científico.

Uma abordagem com essas considerações pode ser estabelecida com a introdução de questões ambientais, políticas, econômicas, éticas, sociais e culturais relativas à ciência e à tecnologia. Segundo Santos e Mortimer (2009), essas questões têm sido geralmente denominadas no inglês como socioscientific issues (SSI) e podem ser traduzidas por questões sociocientíficas ou temas sociocientíficos. A partir da tradução, alguns referenciais consideram a proposição de questões sociocientíficas introduzidas no currículo na forma de perguntas com natureza controversa capazes de suscitar debates, em um processo argumentativo. Outros ponderam as questões sociocientíficas como temas relativos às interações CTS. É possível inferir que diversos referenciais mencionam os termos questões sociocientíficas e temas sociocientíficos para fazer referência ao mesmo conceito. Para o presente trabalho, a abordagem CTS foi considerada a partir do termo temas sociocientíficos. 


\begin{abstract}
A inclusão de temas sociocientíficos é recomendada por todos os artigos revisados, sendo justificada pelo fato de que eles evidenciam as inter-relações dos aspectos da ciência, tecnologia e sociedade propiciarem condições para o desenvolvimento de atitudes de tomada de decisão dos alunos (SANTOS; SCHNETZLER, 2010, p. 81).
\end{abstract}

Para Santos (2002), no que se refere à formação científica e tecnológica, esses temas são relevantes para preparar o cidadão para uma ação social responsável, comprometido com questões ambientais presentes e futuras e para que possam participar das decisões sobre ciência e tecnologia. Cabe destacar que uma abordagem com tal abrangência possui um forte componente interdisciplinar, pois, ao trabalhar as interfaces da ciência, tecnologia e sociedade, permite também embasar questões de relevância social, contribuindo para o envolvimento de diversas áreas de conhecimentos, implicando o campo das Ciências da Natureza e Ciências Humanas.

A oficina, objeto de investigação neste trabalho, teve como tema os aditivos alimentares. A escolha desta temática foi baseada nos principais temas sociocientíficos utilizados em abordagem CTS apontados pela literatura que cita as relações apresentadas por Towse (1986) e Bybee (1987). Os temas foram agrupados por Towse (1986) apud Santos e Schnetzler (2010), tais como: saúde; alimentação e agricultura; recursos energéticos; terra, água e recursos minerais; indústria e tecnologia; ambiente; transferência de informação e tecnologia e ética e responsabilidade social. Enquanto Bybee (1987) apud Santos e Schnetzler (2010) identificou os seguintes temas centrais de cursos CTS: qualidade do ar e atmosfera; fome mundial e fontes de alimentos; guerra tecnológica; crescimento populacional; recursos hídricos; escassez de energia; substâncias perigosas; saúde humana e doença; uso do solo; reatores nucleares; animais e plantas em extinção e recursos minerais. A partir desse levantamento, foi possível relacionar os principais temas apontados por ambos e, com base neles, sugerir possíveis desdobramentos (Quadro 2).

Quadro 2 - Principais temas sociocientíficos.

\begin{tabular}{|c|c|}
\hline Tema & Desdobramentos \\
\hline Saúde & Saúde humana e doenças. \\
\hline Alimentos & Fonte de alimentos, fome mundial e agricultura. \\
\hline Recursos energéticos & Fontes de energia e falta de energia. \\
\hline Terra, Água e Ar & Uso da terra, recursos hídricos e qualidade do ar e atmosfera. \\
\hline Indústria e Tecnologia & Avanços e impactos tecnológicos. \\
\hline Ambiente & Preservação ambiental e poluição ambiental. \\
\hline Tecnologia & Transferência de informação e guerra tecnológica. \\
\hline Ética e Responsabilidade Social & Política, economia, saúde, educação e meio ambiente. \\
\hline
\end{tabular}

Fonte: Elaborado pelas autoras, 2019.

Foi escolhido o tema aditivos alimentares, dando ênfase ao uso de aromas e corantes nos alimentos, considerando que este também pode ser um desdobramento associado ao tema geral alimentos. Ramsey (1993) apud Santos (2002, p. 56) apresenta três critérios para identificar um tema social que permita a discussão de questões relativas à ciência:

a) se é de fato um problema de natureza controvertida, ou seja, se existem opiniões diferentes a seu respeito;

b) se o tema tem significado social;

c) se o tema, em alguma dimensão, é relativo à ciência e à tecnologia. 
Além disso, também aponta a importância dos temas serem vinculados a problemas da vida real dos indivíduos para auxiliar no desenvolvimento da capacidade de tomada de decisão.

$\mathrm{O}$ uso de aromas e corantes em produtos alimentícios, dentro do tema aditivos alimentares, apresentou-se como uma questão pertinente, uma vez que possui natureza controversa no sentido de incitar discussões sobre os benefícios e malefícios de sua produção e consumo; apresenta significado social por estar presente no dia a dia de todos, ou da grande maioria, através do consumo de alimentos que contêm esses aditivos e, por fim, por estar intimamente relacionado ao desenvolvimento da ciência e tecnologia. Portanto, considera-se que esse tema e seus desdobramentos são apropriados em relação aos "critérios" de tema social relativo à ciência, além de atenderem os aspectos caraterizadores da abordagem CTS.

\section{Aromas e corantes como tema para o ensino de química}

A sobrevivência dos seres humanos, entre outros fatores, está diretamente relacionada à alimentação, e o sabor, o odor e a cor são aspectos que influenciam significativamente na escolha e aceitabilidade dos produtos. Com os objetivos de dar ou reforçar o sabor e odor, intensificar ou restaurar a cor e, de modo geral, melhorar a aceitabilidade dos produtos pelos consumidores, o uso de aromas e corantes como aditivos tem se popularizado e contribuído para a mudança no hábito alimentar da população, o que tem chamado atenção dos órgãos reguladores e da comunidade científica como um todo, em relação à incerteza dos impactos da substituição de alimentos in natura por alimentos com essas substâncias.

Diante disso, cabe o questionamento: em que consiste o impacto incerto dos aromas e corantes na alimentação? A mídia e a literatura evidenciam principalmente as implicações desses produtos na saúde, salientando as ocorrências de reações adversas aos aditivos, quer seja aguda ou crônica, como reações tóxicas no metabolismo desencadeantes de alergias, de alterações no comportamento em geral, e carcinogenicidade, esta última observada em longo prazo (POLÔNIO; PERES, 2009). No entanto, cabe também estender os questionamentos às implicações ao meio ambiente, principalmente em relação à retirada de recursos naturais e descarte. $\mathrm{O}$ fato é que esses aditivos abrangem uma série de questões e contraposições importantes, como a composição natural versus a composição sintética; testes de toxicidade versus relatos de impactos na saúde, além dos aspectos de rotulagem.

Pensando na natureza controversa da produção e consumo dessas substâncias, compreende-se que a abordagem de conhecimentos científicos, especialmente os da área da química, dada através de questões que estão imbricadas no tema, pode contribuir para um melhor entendimento de que tipo de substâncias são os aromas e corantes, como são estudados, extraídos e criados e, a partir disso, auxiliar na tomada de decisão em relação à escolha de produtos e aos impactos que esses aditivos podem causar.

$\mathrm{O}$ uso de aromas e corantes como aditivos alimentares foi considerado de grande pertinência frente ao ensino de química por vários motivos. Em primeira instância, demonstrouse interessante por ser um tema presente no cotidiano, uma vez que a maioria das pessoas, em algum momento, já teve ou mantém contato com alimentos que possuem esses aditivos. Desse modo, é um tema comumente presente na sociedade moderna, que apresenta significado humano e social, a partir do qual é possível abordar dados, informações e conceitos sem se distanciar da realidade atual, contribuindo significativamente para o processo de ensinoaprendizagem.

Em segundo lugar, porque pode ser considerado como um tema sociocientífico que permite explorar questões ambientais, políticas, econômicas, éticas, sociais e culturais, além de 
possibilitar o estudo das interfaces da ciência, da tecnologia e da sociedade e articular suas inter-relações em uma mesma proposta, assim como sugere a abordagem CTS. O tema permite explorar com propriedade inúmeras questões que relacionam a ciência, tecnologia e sociedade, evidenciando as contribuições, a influência e os impactos do desenvolvimento científicotecnológico para esta área. É possível demonstrar de que forma os conhecimentos científicos e tecnológicos estão envolvidos na descoberta, estudo e criação desses aditivos que "imitam" produtos que são encontrados na natureza e como são incluídos na alimentação.

O tema também é abrangente considerando a química especificamente. Possibilita abordar conteúdos programáticos da química geral (solubilidade, volatilidade, ponto de fusão, ponto de ebulição), química orgânica (estudo de funções e reações orgânicas), físico-química (soluções, cinética química, termoquímica e equilíbrio químico), química experimental e análise instrumental (extração, destilação, cromatografia, ressonância magnética, espectroscopia). (COSTA et al., 2004; FELIPE; BICAS, 2017; FERREIRA et al., 2018).

Por fim, em terceiro lugar, o tema demonstrou-se pertinente porque envolve uma série de questões que se estendem a uma perspectiva social e que exigem um posicionamento. Compreender os conhecimentos científicos, com destaque para os conhecimentos químicos, e relacioná-los com a produção e consumo de alimentos com aromas e corantes possibilitam, dentre muitas questões, refletir a respeito das diferenças na composição entre produtos. Essa compreensão auxilia, sobretudo, em uma melhor escolha dos produtos para consumo e pode contribuir para o desenvolvimento de senso crítico relacionado ao custo/benefício, além de incitar questionamentos e reflexões em relação aos impactos na saúde e no meio ambiente.

A seguir, serão discutidos como os aspectos abordados até o momento e outros foram considerados na concepção e realização da oficina.

\section{A oficina "Sabor, odor e cor: decifrando o mundo dos aromas e corantes"}

A discussão realizada nesta e nas próximas seções são baseadas na análise das informações e dados obtidos por meio da observação e anotações de campo das pesquisadoras e da resolução das atividades e respostas dos participantes aos questionários (formulário de inscrição e questionário de avaliação) em uma das ofertas da oficina. Os dados obtidos foram analisados de acordo com a Análise de Conteúdo (BARDIN, 1997), organizada em pré-análise, exploração do material e tratamento dos resultados, e inferência e interpretação.

A oficina foi intitulada Sabor, odor e cor: decifrando o mundo dos aromas e corantes, realizada no laboratório interdisciplinar de formação de educadores (LIFE) da própria universidade, teve duração de aproximadamente três horas e foi aberta para todos os interessados. A divulgação foi feita por meio das redes sociais e distribuição de folders em algumas escolas da região. Para participar, os interessados deveriam fazer uma inscrição respondendo um formulário online, que visava caracterizar os participantes, verificar seus conhecimentos prévios e expectativas em relação ao tema. Estas informações foram consideradas na elaboração das atividades da oficina, contribuindo para estruturar e definir os conteúdos, a linguagem utilizada, os materiais e o espaço físico.

\subsection{Perfil dos inscritos}

Foram realizadas treze inscrições, entre as quais sete participaram efetivamente da oficina. A faixa etária dos inscritos variou de 19 a 65 anos, sendo que $38 \%$ dos inscritos tinham entre 19 e 20 anos. A idade dos inscritos indica que o tema da oficina despertou o interesse e 
foi abrangente em relação à faixa etária, demonstrando que as discussões atreladas ao tema podem ser relevantes e atrativas a várias idades. Além disso, vale pontuar que a larga faixa etária entre os participantes configurou um grande desafio em relação a adaptar o conteúdo e as informações que seriam discutidas.

Em relação ao grau de escolaridade, a oficina atingiu tanto o público de ensino básico como o de ensino superior. A maior parte dos inscritos possuía ensino superior incompleto, sendo que $46 \%$ dos inscritos eram estudantes da própria universidade e $8 \%$ de outras instituições; $23 \%$ possuía ensino superior completo em outras universidades e $8 \%$ pela própria instituição; $15 \%$ dos inscritos possuía ensino básico completo.

Duas questões do formulário de inscrição visavam investigar se os participantes consumiam alimentos industrializados e se eles analisavam as informações dos rótulos dos produtos industrializados antes de comprá-los. As respostas indicaram que todos os inscritos consumiam produtos industrializados, sendo que $85 \%$ eram consumidores frequentes e $15 \%$ ocasionais. Desse público, $54 \%$, indicou ter o hábito de analisar o rótulo dos produtos antes de comprá-los. Apesar de ser um pouco mais que a metade dos inscritos, é possível considerar que a leitura e a análise de rótulos não consistem em algo praticado por um número significativo de pessoas, indicando que muitas não possuem conhecimento sobre a composição dos produtos que estão ingerindo.

Em relação ao que conheciam sobre aromas, alguns inscritos alegaram pouco conhecimento e a maioria relacionou seu conhecimento sobre aromas à propriedade de conferir e agregar odor. Alguns inscritos relacionaram o odor a outras características: "Alguns me dão enjoo.” (Inscrito 1); “Aromas são 'cheiros', podendo ser agradáveis ou não. Servem para alertar sobre algum perigo" (Inscrito 12); "São cheiros agradáveis ou não podendo alertar sobre perigos e/ou serem utilizados na medicina alternativa" (Inscrito 13). Enquanto outros manifestaram o conhecimento em relação à existência de aromas naturais e sintéticos, indicando conhecer um pouco sobre a classificação: "Alguns são derivados de frutas, outros de compostos sintéticos" (Inscrito 7); "Que há existência de aromas naturais e artificiais" (Inscrito 8); e ainda, relacionaram os aromas industrializados a impactos para a saúde: "Os aromas são os cheiros dos alimentos e muitas vezes são industrializados, o que podem provocar problemas de saúde" (Inscrito 6).

Em relação ao que conheciam sobre os corantes, alguns participantes mencionaram a propriedade de conferir cor aos produtos, inclusive aos alimentos. Muitos explicaram o que conheciam sobre corantes, citando os riscos e impactos: "Alguns podem dar alergias a algumas pessoas" (Inscrito 1); “Os corantes são responsáveis por dar coloração agradável aos alimentos e muitas vezes são industrializados, causando problemas na saúde se consumido de forma excessiva" (Inscrito 6); "Podem ser perigosos" (Inscrito 7); Mencionaram também alguns aspectos relacionados à classificação: "Substâncias naturais ou artificiais utilizadas para colorir algo. Pode dar alergia" (Inscrito 12). Todos os inscritos responderam que a produção e o consumo de aromas e corantes podem trazer algum dano. No entanto, apenas um inscrito mencionou algum dano ao meio ambiente: "são utilizados em roupas ou produtos alimentícios e que podem poluir a água" (Inscrito 8).

As questões discutidas até então evidenciam uma contradição: de um lado, a suspeita dos inscritos em relação aos malefícios que os aromas e corantes podem causar e, de outro, o consumo frequente de alimentos industrializados nos quais são inseridos esses aditivos. Mesmo pressupondo os riscos, parte significativa dos inscritos não possuía o hábito de ler os rótulos dos alimentos, ou seja, não se informavam sobre os componentes inseridos nos produtos que estão consumindo. 
Em relação às expectativas iniciais, os inscritos indicaram a vontade de aprender e conhecer mais sobre o assunto, o que indicou a busca por algo de caráter informativo. Além disso, outra expectativa foi em reconhecer os aromas e corantes no dia a dia, denotando o desejo de compreender como esses aditivos estão presentes na própria realidade cultural: "Conhecer mais sobre como os aromas e corantes fazem parte do meu dia a dia" (Inscrito 7).

Os inscritos demonstraram interesse em compreender melhor danos associados a esses aditivos: "Espero conhecer um pouco mais sobre corantes e aromatizantes, sobre problemas na saúde e como identificar em um produto" (Inscrito 6); "Conhecer um pouco mais sobre a produção de corantes, matérias primas, etc." (Inscrito 5). Também foi possível verificar a expectativa com relação a informações que pudessem despertar o interesse: "Acredito que vai trazer muita informação interessante" (Inscrito 1); e que estimulassem o senso crítico: "Desenvolver conhecimento e senso crítico" (Inscrito 8).

\subsection{Criação e realização da oficina}

Para elaborar uma oficina temática é preciso considerar vários fatores que podem ser compreendidos como etapas da elaboração dessa estratégia metodológica. A sistematização dessas etapas teve como base as considerações apresentadas por Marcondes (2008) e é apresentada na Figura 1. O planejamento é uma das etapas mais importantes, pois é quando todos os recursos e estratégias, como experimentação, leitura e discussão de textos, que subsidiam o conteúdo das atividades são estudados e definidos. São necessárias leitura, reflexão e discussão na escolha e criação das atividades sem perder os propósitos do projeto de extensão, do ensino e aprendizagem e da pesquisa.

Figura 1- Etapas envolvidas na elaboração da oficina temática.

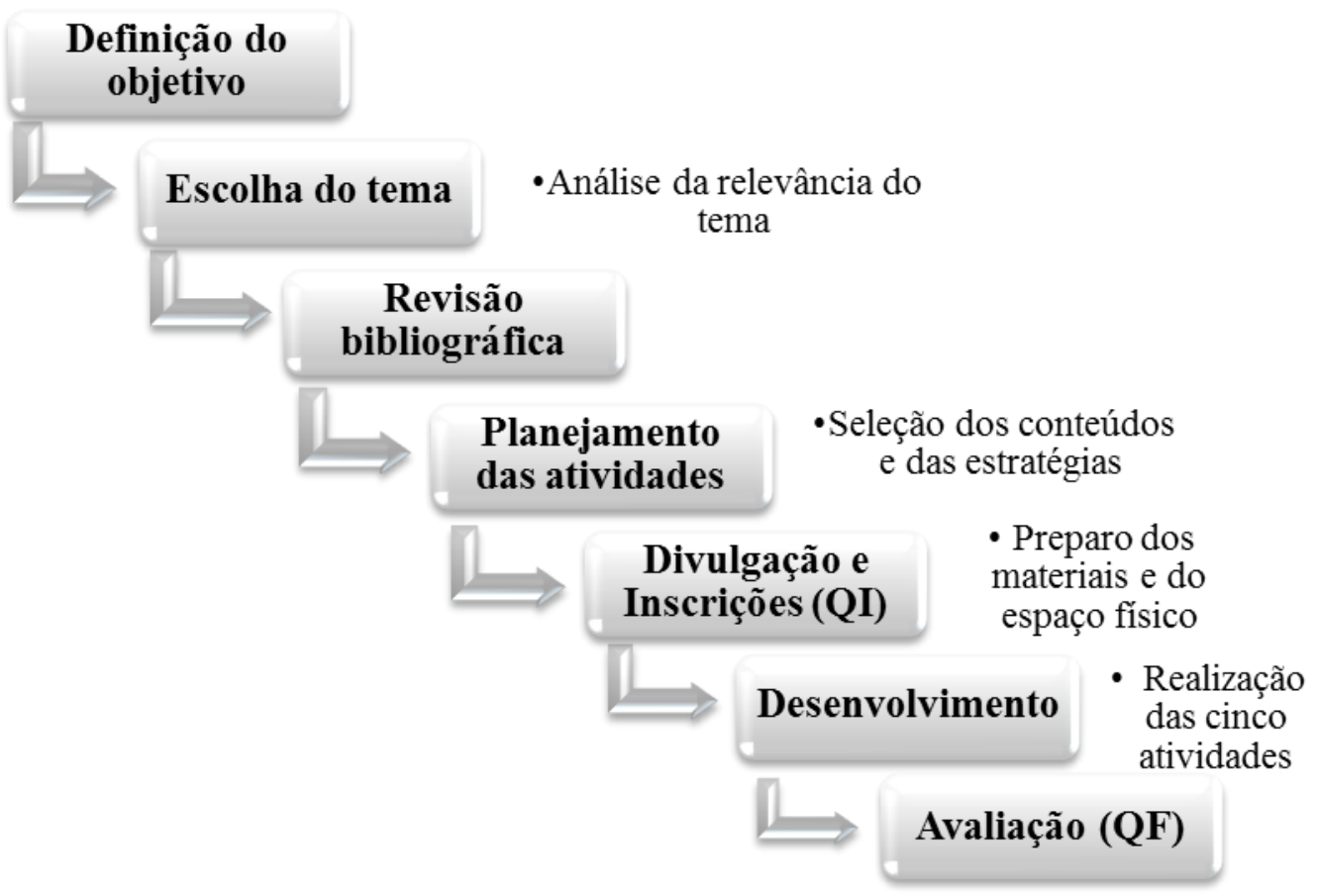

Fonte: Elaborado pelas autoras, 2019. 
O objetivo da oficina foi explorar os conhecimentos científicos envolvidos na caracterização e fabricação dos aromas e corantes, através de atividades que valorizassem a participação e reflexão e que pudessem auxiliar na tomada de decisões em relação aos impactos que a produção e o consumo de produtos que contêm esses aditivos podem trazer para a saúde e meio ambiente. Cada atividade que compôs a oficina foi estruturada com base em seus objetivos e nos aspectos caracterizadores da abordagem CTS, buscando envolver recursos que auxiliam nos processos de ensino e aprendizagem em ciências e na formação da cidadania. Tanto na escolha quanto na elaboração das estratégias, os aprendizados proporcionados no contexto da formação inicial de professores foram de suma importância para a autora da oficina, já que, nesta fase de elaboração, foram resgatadas algumas estratégias estudadas durante o curso de licenciatura, o que reforça a contribuição de projetos de extensão desta natureza nesse contexto, sobretudo para estudantes que não têm a oportunidade de participar de atividades extracurriculares em escolas da educação básica como os programas de iniciação à docência, por exemplo. No Quadro 3, são apresentadas as estratégias e objetivos estabelecidos para cada atividade que compôs a oficina.

Quadro 3 - Atividades desenvolvidas na oficina.

\begin{tabular}{|c|c|c|}
\hline Atividade & Estratégia & Objetivos \\
\hline $\begin{array}{l}\text { Atividade } 1 \\
\text { "Somos o que } \\
\text { comemos!" Mas o } \\
\text { que estamos } \\
\text { comendo afinal? }\end{array}$ & $\begin{array}{l}\text { Avaliação sensorial de } \\
\text { produtos (suco natural, } \\
\text { "suco em pó" e suco } \\
\text { industrializado); } \\
\text { Trecho de filme. }\end{array}$ & $\begin{array}{l}\text { Levantar os conhecimentos prévios. } \\
\text { Estimular a discussão e participação. } \\
\text { Incitar questionamentos e reflexões sobre as } \\
\text { características e diferenças entre produto. } \\
\text { Definir e caracterizar os aditivos alimentares, } \\
\text { especialmente os aromas e corantes. } \\
\text { Apresentar aspectos históricos e culturais. }\end{array}$ \\
\hline $\begin{array}{l}\text { Atividade } 2 \\
\text { Decifrando a } \\
\text { composição do } \\
\text { "suco em pó" }\end{array}$ & Experimentação & $\begin{array}{l}\text { Estimular a curiosidade e a capacidade investigativa. } \\
\text { Apresentar os conceitos científicos envolvidos nas } \\
\text { técnicas de destilação e cromatografia. } \\
\text { Apresentar, discutir e caracterizar os componentes do } \\
\text { "suco em pó". }\end{array}$ \\
\hline $\begin{array}{c}\text { Atividade } 3 \\
\text { Decifrando os } \\
\text { aromas e corantes }\end{array}$ & $\begin{array}{l}\text { Avaliação sensorial de } \\
\text { aromas, corantes e } \\
\text { matérias primas. }\end{array}$ & $\begin{array}{c}\text { Incitar questionamentos sobre as propriedades físico- } \\
\text { químicas dos aromas e corantes; } \\
\text { Abordar conhecimentos da área da química para } \\
\text { explicar as propriedades físico-químicas dos aromas e } \\
\text { corante. } \\
\text { Caracterizar os aromas e corantes dos "sucos em pó" } \\
\text { utilizados na atividade } 2 \text {. } \\
\text { Apresentar informações do âmbito industrial e } \\
\text { tecnológico. } \\
\text { Incitar questionamentos e reflexões sobre os impactos } \\
\text { na saúde e meio ambiente. }\end{array}$ \\
\hline $\begin{array}{l}\text { Atividade } 4 \\
\text { O que estamos } \\
\text { comprando? }\end{array}$ & $\begin{array}{l}\text { Análise do rótulo de } \\
\text { alimentos disponíveis } \\
\text { no supermercado. }\end{array}$ & $\begin{array}{l}\text { Apresentar informações sobre as normas de rotulagem. } \\
\text { Instruir a interpretação e leitura de rótulos. }\end{array}$ \\
\hline $\begin{array}{l}\text { Atividade } 5 \\
\text { Criando e } \\
\text { comprando! }\end{array}$ & Resolução de desafios. & $\begin{array}{c}\text { Incitar a capacidade inventiva, argumentação e tomada } \\
\text { de decisão. } \\
\text { Estimular o trabalho em grupo. } \\
\text { Verificar os aprendizados sobre as informações } \\
\text { abordadas nas atividades anteriores. }\end{array}$ \\
\hline
\end{tabular}

Fonte: Elaborado pelas autoras, 2019. 
A oficina iniciou-se com uma introdução ao tema, apresentação de um panorama geral sobre os aromas e corantes e discussão sobre alguns aspectos históricos e culturais. Na Atividade 1, os participantes foram convidados a degustar e avaliar amostras de sucos. A atividade estimulou os participantes a exporem suas impressões e opiniões e, sobretudo, a refletirem e se questionarem sobre as diferenças entre os produtos. Também foi possível verificar as ideias iniciais dos participantes, o que subsidiou as discussões seguintes e proporcionou um momento de interação mais descontraído. Quando questionados sobre a definição de aroma, os participantes relacionaram ao cheiro, mencionando também o aroma relacionado às memórias olfativa e afetiva ou, ainda, como sinal de alerta como quando os alimentos estão estragados. Grande parte dos participantes associava o aroma apenas à propriedade de atribuir odor, tal como foi indicado no formulário de inscrição, uma vez que nenhum deles mencionou o sabor.

As definições apresentadas pela Agência Nacional de Vigilância Sanitária (ANVISA, 1997) foram utilizadas na discussão sobre o que são, para que servem e como os aditivos são incorporados na produção de alimentos pela indústria. Foram abordados os tipos de aditivos, especificando o uso de aromas e corantes. Para embasar a definição de aroma e corante, foi realizada uma breve explicação sobre o processo histórico de criação e utilização desses produtos, apresentando informações sobre os aspectos culturais e históricos, considerando a importância de trabalhar a História da Ciência e Tecnologia. De acordo com Reis, Silva e Buza (2012, p. 3), "a História da Ciência é fundamental para ressaltar o papel da ciência como parte da cultura humana, acumulada ao longo dos séculos". Para os mesmos autores, trabalhar com a História da Ciência pode contribuir a inserção conceitos científicos dentro de uma realidade humana, valorizando a ciência como uma construção humana, que envolve também aspectos negativos e falhas, além do fato de demonstrar que os conceitos científicos são modificados com o passar do tempo até a consolidação de um paradigma dominante e melhor aceito (REIS; SILVA; BUZA, 2012).

Sobre a explicação relacionada à compreensão do que é um aroma, notou-se surpresa dos participantes em relação à sua classificação, principalmente em relação às substâncias sintéticas, uma vez que se trata de matérias primas que não são encontradas na natureza e que foram criadas pelo ser humano. Comparando com as informações coletadas inicialmente, percebeu-se que apesar de terem mencionado algo que remetia à existência de aromas naturais e sintéticos, a ideia de aroma sintético ainda causava estranheza, sendo, de certa forma, um assunto sobre o qual não tinha domínio.

Para auxiliar na explicação do processo histórico, foram utilizados trechos do filme Perfume, a história de um assassino (PERFUME, 2006). O filme foi um recurso utilizado para demonstrar como estes produtos eram criados e quais técnicas de fabricação eram utilizadas na época em comparação com os métodos utilizados na sociedade atualmente. Também auxiliou no debate sobre as transformações da ciência neste ramo, evidenciando as influências do desenvolvimento da ciência e da tecnologia, bem como a importância do contexto social, econômico e cultural. Este filme foi considerado oportuno para abordar o contexto da sociedade francesa do século XVIII, ilustrando principalmente as fases de estudo, criação e produção de aromas e fragrâncias.

De modo geral, a Atividade 1 conseguiu explorar os objetivos pretendidos. Os momentos de análise sensorial e interação com as amostras de substâncias aromáticas foram os que mais contribuíram para a participação e discussão, por isso cabe ressaltar a importância de estratégias que estimulem a interação com diferentes materiais e produtos em oficinas temáticas. Além disso, cabe destacar a relevância de disponibilizar tempo suficiente para que todos interajam ativamente e tranquilamente com os materiais apresentados. 

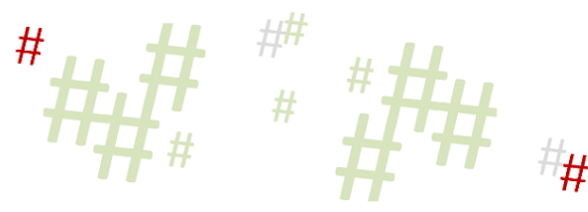

A Atividade 2 consistiu na realização de dois experimentos - destilação simples e cromatografia em papel - para discutir a composição dos "sucos em pó"1 e as propriedades dos aromas e corantes que fazem parte de sua formulação, além de conceitos inerentes às técnicas de análise. $O$ intuito principal dessa atividade foi promover o contato com atividades experimentais, além de reconhecer o uso de aromas e corantes no "suco em pó", possibilitando a identificação de algumas de suas características. Todos os experimentos foram realizados com materiais de fácil acesso e baixo custo, como lâmpadas, velas, filtro de café, copos, entre outros. A destilação simples foi realizada por meio do aquecimento de uma solução aquosa de "suco em pó" e condensação do vapor produzido neste processo. Equipamentos laboratoriais de destilação foram substituídos pelo bulbo de vidro de uma lâmpada incandescente conectado a uma mangueira de borracha. Uma vela foi utilizada como fonte de calor. A cromatografia em papel foi realizada utilizando filtro de café, copos plásticos e álcool. Pequenas gotas da solução de "suco em pó" foram adicionadas no papel (fase estacionária) para que o álcool (fase móvel) interagisse com as partículas de corantes.

No experimento de destilação, os participantes ficaram envolvidos com os procedimentos, principalmente no momento de aquecer a solução do "suco em pó" com o auxílio da vela. Além disso, ficaram muito surpresos quando notaram a formação de gotículas aromáticas na mangueira utilizada como condensador. Na realização da cromatografia em papel, a presença de pigmentos com diferentes colorações foi verificada, contrapondo a ideia de que apenas uma substância atribuía cor ao refresco. A discussão sobre os experimentos permitiu explorar os conceitos científicos básicos envolvidos nas técnicas de destilação e cromatografia, além de revelar presença dos aditivos. Sobretudo, foram estratégias que incitaram a curiosidade, capacidade investigativa e o trabalho em grupo em todas as etapas de realização, visto o comportamento e os comentários dos participantes durante a atividade.

Na discussão sobre a composição dos sucos, refrescos e néctares, a quantidade excessiva de açúcar presente na maioria desses produtos despertou o interesse dos participantes. Houve também a discussão e a problematização sobre o uso do termo "suco em pó", bastante comum, considerando a potencialidade de induzir o consumidor ao erro. A reduzida quantidade de fruta nos produtos também foi evidenciada. Um dos participantes comentou sobre a utilização do suco de maçã na composição de várias bebidas para adoçar, justamente por ser um produto mais barato, e perguntou: "O suco de maçã também entra na porcentagem de suco ou néctar de fruta?". Esse e outros comentários evidenciaram o envolvimento com as informações apresentadas e os estímulos às reflexões sobre a composição dos produtos e suas diferenças.

Amostras dos aromas e corantes presentes na composição dos "sucos em pó" utilizados nos experimentos da Atividade 2 foram apresentadas aos participantes na Atividade 3 para análise sensorial. Os participantes tiveram contato com amostras do aroma idêntico ao natural de laranja e dos corantes amarelo crepúsculo e tartrazina presentes no "suco" de laranja; amostras do aroma idêntico ao natural de uva e dos corantes vermelho 40; bordeaux e azul brilhante, presentes no "suco" de uva. A interação com os corantes foi a que mais chamou atenção, principalmente por apresentarem coloração forte e atrativa.

Nesse momento, foi retomada a classificação dos tipos de aromas e corantes e apresentadas informações como de onde são extraídos ou sintetizados, características sensoriais e impactos. Além disso, esta atividade foi proposta para levantar algumas propriedades físicoquímicas que estão envolvidas na caracterização e estudo desses aditivos. A análise desses produtos envolve a compreensão de diversas propriedades, como o estado físico, odor, cor, pH,

${ }^{1}$ Nome popular para preparado sólido para refresco. 
temperatura (ponto de ebulição, ponto de fusão, ponto de fulgor), densidade e solubilidade e, portanto, julgou-se pertinente explorá-las durante a discussão através de questionamentos.

Foram apresentados alguns exemplos de corantes naturais e, a partir disso, os participantes foram questionados sobre a diferença entre os produtos naturais e sintéticos. Em seguida, a discussão foi direcionada para a realização da Atividade 4, que consistiu na compreensão da aplicação de aromas e corantes em produtos disponíveis nos supermercados. Foram abordadas as informações obrigatórias que devem constar nos rótulos e como devem ser apresentadas, de modo a não induzir o consumidor ao erro. Para esta atividade, foi apresentada uma série de embalagens de produtos para que os participantes analisassem seus rótulos, buscando reconhecer a presença de aditivos na composição, bem como as informações discutidas anteriormente. O propósito foi de atentar e instruir os participantes sobre a importância da leitura dos rótulos. Um participante identificou a presença de um dos corantes utilizados na atividade anterior (corante azul brilhante) em um dos rótulos, enquanto outro destacou a quantidade de açúcar agregada nos alimentos. Essa atividade proporcionou aos participantes um momento de interação com os rótulos de diversos alimentos, possibilitando que interpretassem e consultassem informações, com as quais, talvez, nunca tivessem se preocupado, conforme informações obtidas no formulário de inscrição.

$\mathrm{Na}$ Atividade 5, um grupo de participantes representou integrantes de uma equipe de pesquisa e desenvolvimento de uma empresa de produtos alimentícios e o outro grupo representou uma família consumidora. A atividade envolveu a resolução do desafio de criar, teoricamente, três produtos inovadores que deveriam conter matérias primas aromáticas e corantes em sua formulação. Para isso, foram entregues algumas fichas para os grupos com informações sobre nove corantes e nove matérias primas aromáticas. Dentre as informações, foram indicados nas fichas o nome do aditivo, classificação, molécula, extração ou síntese, cor, sabor, odor, em quais produtos são utilizados, custo e impactos que poderiam causar. Com base nessas informações, o grupo da equipe de pesquisa e desenvolvimento deveria escolher quais deles apresentariam a melhor relação custo/benefício preservando as características sensoriais padrões e que chamando atenção da clientela para compor três produtos inovadores. Em contrapartida, o grupo que representava a família deveria escolher e justificar a compra de apenas um dos produtos criados pelo outro grupo, levando em consideração principalmente os fatores relacionados aos riscos, impactos e custo.

O intuito dessa atividade era de que os participantes pudessem trabalhar em grupos e utilizar os aprendizados explorados durante as outras atividades da oficina para simular situações de criação e compra, exercitando a capacidade inventiva, a argumentação e a tomada de decisão para discernir qual seria o melhor produto a ser criado e comprado. Os participantes foram além do que era esperado, assumiram o desafio dado e optaram por apresentar mais opções de produtos, visando atingir todo tipo de clientela. Em relação aos riscos e impactos dos aditivos, durante a atividade, um dos participantes comentou: "O impacto desses produtos me assusta muito". E acrescentou: "Eu sabia que os corantes poderiam causar alergias, mas não tinha ideia de quantos males poderiam causar".

Em suma, cabe retomar que o objetivo deste trabalho envolve o desenvolvimento de uma oficina temática baseada na abordagem CTS. No Quadro 4, é apresentado como a abordagem CTS foi contemplada em cada uma das atividades desenvolvidas na oficina, considerando as relações estabelecidas no Quadro 1, que traz os nove aspectos da abordagem CTS. 
Quadro 4 - Relação entre os nove aspectos da abordagem CTS e o planejamento das atividades da oficina.

\begin{tabular}{|c|c|}
\hline Aspetos de CTS & Atividades da oficina \\
\hline Natureza da Ciência & $\begin{array}{l}\text { Descoberta, estudo e uso de matérias primas e corantes encontrados na } \\
\text { natureza e que podem ser isolados e incorporados na alimentação. }\end{array}$ \\
\hline Natureza da Tecnologia & $\begin{array}{l}\text { Descoberta, estudo e uso de aditivos alimentares para auxiliar na } \\
\text { conservação de produtos. }\end{array}$ \\
\hline Natureza da Sociedade & $\begin{array}{l}\text { Os aditivos, quando são incorporados na formulação de um alimento, } \\
\text { devem ser devidamente informados nos rótulos. }\end{array}$ \\
\hline $\begin{array}{l}\text { Efeito da Ciência sobre a } \\
\text { Tecnologia }\end{array}$ & $\begin{array}{l}\text { A partir do desenvolvimento de técnicas de destilação e cromatografia } \\
\text { foi possível extrair e sintetizar substâncias naturais bem como criar } \\
\text { substâncias sintéticas. }\end{array}$ \\
\hline $\begin{array}{l}\text { Efeitos da Tecnologia sobre } \\
\text { a Sociedade }\end{array}$ & $\begin{array}{l}\text { Em função do desenvolvimento de produtos coloridos e saborosos, a } \\
\text { sociedade tornou-se consumidora de alimentos com aditivos químicos. }\end{array}$ \\
\hline $\begin{array}{l}\text { Efeito da Sociedade sobre a } \\
\text { Ciência }\end{array}$ & $\begin{array}{l}\text { Com a divulgação dos riscos e impactos do uso de aromas e corantes, a } \\
\text { sociedade tem mudado o hábito alimentar e com isso, pressionado o } \\
\text { desenvolvimento de produtos com componentes naturais. }\end{array}$ \\
\hline $\begin{array}{l}\text { Efeito da Ciência sobre a } \\
\text { Sociedade }\end{array}$ & $\begin{array}{l}\text { A divulgação de conhecimentos científicos sobre os impactos do } \\
\text { consumo e produção de aromas e corantes sintéticos fez com que as } \\
\text { pessoas buscassem produtos naturais. }\end{array}$ \\
\hline $\begin{array}{l}\text { Efeito da Sociedade sobre a } \\
\text { Tecnologia }\end{array}$ & $\begin{array}{l}\text { A exigência dos consumidores tem estimulado a pesquisa de novos } \\
\text { produtos para atender as expectativas do mercado consumidor. }\end{array}$ \\
\hline $\begin{array}{l}\text { Efeito da Tecnologia sobre } \\
\text { Ciência }\end{array}$ & $\begin{array}{l}\text { A criação de equipamentos tecnológicos possibilitou estudar e criar } \\
\text { matérias primas aromáticas e corantes que não são encontrados na } \\
\text { natureza. }\end{array}$ \\
\hline
\end{tabular}

Fonte: Elaborado pelas autoras, 2019.

\subsection{Avaliação dos participantes}

As informações e dados sobre a avaliação foram obtidos por meio do questionário respondido pelos sete participantes no final da oficina. Todos os participantes apreciaram a oficina: "Pois aprendi sobre os riscos e impactos dos corantes e aromatizantes"; "É algo de importância social, e que muitas vezes não nos damos conta do risco que corremos mesmo optando por naturais"; "Apresentou muitas informações sobre assuntos que geralmente passam despercebidos pela maioria das pessoas". Além dos riscos e impactos, mencionaram a abordagem de diversas informações, apresentando um panorama geral do tema: "Conta desde quando é usado o aroma e o corante, sua forma de ser extraída, riscos pra saúde, etc.”; além disso, gostaram da oficina por apresentar essas informações de forma clara e por relacioná-las ao cotidiano: "Explanou bem os termos, interligando teoria e cotidiano"; "Foi muito legal, prática esclarecedora". Por fim, outro motivo que agradou foi o fato de explorar trabalhos em grupos: "Eu achei muito legal o fato de interagir com outras pessoas e se aprofundar em determinados assuntos".

Seis participantes afirmaram que as informações abordadas na oficina os fizeram repensar a respeito da produção e consumo de produtos que contêm aromas e corantes sintéticos. Dentre as justificativas, a maioria delas também mencionou os riscos e impactos associados: "Fez com que eu percebesse alguns fatores muito importantes relacionados, principalmente à saúde"; "Porque é minha saúde que está em jogo"; "Pelo impacto causado na saúde". Além disso, foi possível notar que os riscos inerentes aos corantes foram os mais impactantes: "Sabia que havia pontos negativos com relação ao uso dos corantes, pensando só 
em alergias, não tinha ideia nas demais influências". Por fim, vale ressaltar o impacto que o conteúdo da oficina causou, principalmente em relação às escolhas para consumo: "Porque chamou minha atenção sobre os malefícios dos corantes. Eu aboli suco em pó da minha vida a partir de hoje"; "Agora realmente pensarei mais no que comprar". Em contrapartida, um participante apontou que a oficina não possibilitou essa reflexão, pois "apesar de saber que muitas coisas têm riscos, infelizmente vendo pela lógica individual são produzidos em longa escala e em preço menor, é neutro".

Entre os aspectos da oficina que mais chamaram a atenção dos participantes estão alguns dos conteúdos abordados, como os "efeitos colaterais dos corantes, como a hiperatividade" e "saber da composição de produtos e a aplicação de aditivos em outros". Outros voltaram a atenção para a parte experimental: "Quando fizemos o processo de destilação do suco [...] para extrair o aroma de uva"; e para a discussão realizada em torno dela, no momento em que foi detalhada a composição do "suco em pó": "Na parte do suco em pó, pois descobri que ele possui quase nada de suco, é praticamente puro açúcar". Alguns participantes consideraram o momento da Atividade 5, como é possível perceber pelas respostas: "A atividade final, pois teve uma interação em grupo e uma atividade de consulta"; "A atividade 5, dinâmica onde colocamos alguns dos conhecimentos em prática, em grupos". E, por fim, além dos riscos e da Atividade 5, consideraram também os aspectos históricos: "O conhecimento a respeito dos pontos negativos do uso; história desse tema e a atividade final".

Com base nas respostas é possível considerar que todas as atividades, em algum momento, abordaram algo que foi julgado interessante, incluindo principalmente as questões de riscos e impactos, informações de diferentes aplicações, informações sobre a composição de produtos e aspectos históricos. Vale ressaltar, porém, que a Atividade 5 foi julgada pela maioria como o momento mais atrativo.

\subsection{Indicadores das contribuições da abordagem CTS}

Para a avaliação das contribuições da oficina em relação à formação pautada na abordagem CTS, foram utilizados os indicadores apresentados por Dias (2016), que fez uma adaptação das áreas propostas por Yager e McCormack (1989 apud SANTOS; SCHNETZLER, 2010). Os indicadores foram considerados associando as competências (domínios) esperadas que os participantes desenvolveriam através de atitudes, que foram reconhecidas como descritores. Desse modo, cada indicador apresenta uma competência a ser investigada a partir de descritores específicos. Essas relações foram distribuídas da seguinte maneira:

a) conhecimento e compreensão - abrange a análise do domínio da informação associado aos descritores de interpretação, problematização e discussão;

b) exploração e descoberta - abrange a análise do domínio do processo da ciência associado ao descritor da investigação;

c) imaginação e criação - abrange a análise do domínio da criatividade associado ao descritor de criatividade;

d) sensibilização e valorização - abrange a análise do domínio de opiniões associado ao descritor de argumentação e participação;

e) uso e aplicação - abrange a análise do domínio de aplicações e conexões associado ao descritor de reflexão.

O Quadro 5 apresenta a relação das atividades desenvolvidas na oficina associadas a esses indicadores da abordagem CTS. 
Quadro 5 - Atividades da oficina que contemplaram os indicadores da abordagem CTS.

\begin{tabular}{|c|c|c|c|}
\hline Indicadores & Competência & Descritores & Atividades \\
\hline \multirow{2}{*}{$\begin{array}{c}\text { Conhecimento e } \\
\text { compreensão }\end{array}$} & Domínio da informação & Interpretação & 4 e 5 \\
\cline { 3 - 4 } & & Problematização & 5 \\
\cline { 3 - 4 } Exploração e descoberta & $\begin{array}{c}\text { Domínio do processo da } \\
\text { ciência }\end{array}$ & Discussão & $1 ; 2 ; 3$ e 5 \\
\hline Imaginação e criação & Domínio da criatividade & Criatividade & 5 \\
\hline Sensibilização e valorização & Domínio de opiniões & Argumentação & 5 \\
\cline { 3 - 4 } & Participação & $1 ; 2 ; 3 ; 4$ e 5 \\
\hline Uso e aplicação & $\begin{array}{c}\text { Domínio de aplicações e } \\
\text { conexões }\end{array}$ & Reflexão & 1 , 2; 3; 4 e 5. \\
\hline
\end{tabular}

Fonte: Elaborado pelas autoras, 2019.

Os indicadores da abordagem CTS foram contemplados em, pelo menos, uma atividade da oficina. Vale destacar a Atividade 5, que foi a mais abrangente e explorou todos os indicadores. Desse modo, pode-se inferir que esta apresenta uma importância significativa em relação à abordagem CTS, pois conseguiu articular, em algum momento, todos os descritores, explorando a interpretação, problematização, discussão, investigação, criatividade, argumentação, participação e reflexão. Destacam-se também os descritores relacionados à discussão, participação e reflexão que foram explorados pela maioria das atividades da oficina e, portanto, foram "atitudes" bastante incentivadas em sua realização.

Os participantes também indicaram, no questionário final, em uma escala de zero a cinco (considerando zero para nada, um para pouco, três, razoável, quatro muito e cinco para significativamente) as contribuições da oficina no estímulo de cada um dos descritores. Nenhum dos participantes assinalou zero, um ou dois para quaisquer indicadores.

Esses resultados reforçam que a oficina temática pode explorar de forma significativa as áreas de domínio do ensino de ciências, o que possibilita a compreensão de que esta proposta apresentou contribuições importantes para os processos de ensino e aprendizagem em ciências. As atividades abordaram estratégias que foram eficazes para estimular e contribuir para o exercício dos descritores, possibilitando que os participantes se depararem com situações em que fosse necessário interpretar, problematizar, discutir, investigar, criar, argumentar, participar e refletir. A partir dessas considerações, entende-se que a prática desses descritores pode contribuir para uma compreensão mais significativa de assuntos e situações, o que possibilita o desenvolvimento de atitudes mais conscientes relacionadas à tomada de decisões, participação e posicionamento crítico.

\section{Considerações finais}

Foi desenvolvida uma oficina temática baseada na abordagem CTS para abordar um tema sociocientífico, detalhando informações sobre a produção e o consumo de aromas e corantes. A oficina foi elaborada visando analisar as possíveis contribuições da abordagem CTS no trabalho com oficinas temáticas. Além disso, desejou-se contribuir para a divulgação científica, bem como facilitar e estimular a motivação para a aprendizagem de conhecimentos científicos. 
Verificou-se que a oficina atendeu os aspectos da abordagem CTS, uma vez que articulou as interfaces e os efeitos da natureza da Ciência, da Tecnologia e da Sociedade e contemplou todos os indicadores envolvidos em sua avaliação. Além disso, a metodologia utilizada contribuiu significativamente para divulgar conhecimentos científicos a uma larga faixa etária, abrangendo várias localidades e níveis escolares, de forma descontraída, próxima, fazendo uso de diversas estratégias e utilizando materiais de baixo custo e fácil acesso, como lâmpadas incandescentes, vela, copos descartáveis, pedaços de mangueira e filtro de café.

As análises indicaram que a oficina pode ser uma estratégia para promover estudos sobre a ciência de forma interligada à tecnologia e à sociedade, apresentando os conhecimentos científicos inerentes a situações presentes no cotidiano que vão ao encontro da realidade cultural dos participantes, o que favorece a ressignificação dos aprendizados.

Cabe destacar também que a elaboração da oficina temática colaborou para que os licenciandos envolvidos pudessem explorar os conhecimentos aprendidos durante a graduação, uma vez que sua criação envolveu várias etapas, que incluíram leitura, pesquisa, planejamento, desenvolvimento e investigação, fatores que favorecem a formação docente de qualidade. Todas as etapas de elaboração foram importantes, no entanto a etapa de planejamento das atividades foi a mais desafiadora, pois demandou colocar em prática fundamentos teóricos. A realização deste trabalho estimulou a possibilidade de desenvolver além de exercitar atitudes de reflexão-ação voltadas ao desenvolvimento de metodologias com potencialidades para aplicações nas escolas.

Considera-se que a oficina temática desenvolvida pode ser facilmente adaptada e aplicada a todos os níveis escolares, uma vez que aborda conteúdos pertinentes a todos os públicos. Além disso, as atividades da oficina podem ser utilizadas para compor um planejamento de aulas, fundamentando uma sequência didática, por exemplo. No entanto, é necessário considerar algumas limitações. como tempo disponível para aula, salas numerosas, os conhecimentos científicos a serem explorados em cada nível escolar e os materiais disponíveis na escola.

\section{Referências}

ANVISA. Portaria n ${ }^{\circ}$ 540, de 27 de outubro de 1997. Aprova o Regulamento Técnico: Aditivos Alimentares - definições, classificação e emprego. Diário Oficial da União: Poder Executivo, Brasília, DF, 28 de outubro de 1997. Disponível em: http://portal.anvisa.gov.br/documents/33916/391619/PORTARIA_540_1997.pdf/3c55fd22d503-4570-a98b-30e63d85bdad. Acesso em: 23 nov. 2019.

BARDIN, Laurence. Análise de conteúdo. Lisboa: Edições 70, 1977. 225 p.

BYBEE, Rodger W. Science education and the science - technology - society (STS) theme. Science Education, v. 71, n. 5, p. 667-683, 1987.

COSTA, Thiago Santangelo et al. Confirmando a Esterificação de Fischer por Meio dos Aromas. Química Nova na Escola, São Paulo, v. 7, n. 19, p. 36-38, mai. 2004. Disponível em: http://qnesc.sbq.org.br/online/qnesc19/a11.pdf. Acesso em: 13 out. 2019.

CUNHA, Alexander Monteiro. Ciência, tecnologia e sociedade na óptica docente: construção e validação de uma escala de atitudes. 2008. 112 f. Dissertação (Mestrado em educação) - Faculdade de Educação, Universidade Estadual de Campinas, Campinas, 2008. 
DIAS, Ana Carolina. Química, Consumismo e Cosméticos: uma proposta de oficina temática com abordagem CTS. 2016. 76 f. Trabalho de conclusão de curso (Graduação em Licenciatura Química) - Universidade Federal de São Carlos, Araras, 2016.

FELIPE, Lorena O.; BICAS, Juliano L. Terpenos, aromas e a química dos compostos naturais. Química Nova na Escola, São Paulo, v. 39, n. 2, p. 120-130, maio 2017. Disponível em: http://qnesc.sbq.org.br/online/qnesc39_2/04-QS-09-16.pdf. Acesso em: 13 out. 2019.

FERREIRA, Wendel M. et al. Corantes: Uma Abordagem com Enfoque Ciência, Tecnologia e Sociedade (CTS) Usando Processos Oxidativos Avançados. Química Nova na Escola, São Paulo, v. 40, n. 4, p. 249-257, nov. 2018. Disponível em:

http://qnesc.sbq.org.br/online/qnesc40_4/05-RSA-36-17.pdf. Acesso em: 22 mar. 2020.

GARCÊS, Ana Karina Macedo. Oficinas temáticas no desenvolvimento do ensino de química para alunos do ensino médio química. 2016. Trabalho de conclusão de curso (Graduação em Química) - Universidade Federal do Maranhão, São Luís, 2016.

MARCONDES, Maria Eunice Ribeiro. Proposições metodológicas para o ensino de química: oficinas temáticas para aprendizagem da ciência e o desenvolvimento da cidadania. Em Extensão, Uberlândia, v. 7, p. 67-77, 2008.

OLIVEIRA, Carolina Costa de. et al. Oficina temática no ensino de química: trabalhando uma proposta didática com o tema " A química dos Refrigerantes" para alunos do Ensino Médio. In: III ENCONTRO DE INICIAÇÃO À DOCÊNCIA DA UEPB, 2012, Campina Grande. Anais [...]. Campina Grande: UEPB, 2012. Disponível em: http://www.editorarealize.com.br/revistas/eniduepb/trabalhos/Modalidade_6datahora_04_10_ 2013_23_56_52_idinscrito_660_535e30ccf5c3de9ed5b4ccc981177a40.pdf. Acesso em: 14 out. 2019.

PERFUME: The Story of a Murderer. Direção: Tom Tykwer. Produção: Andrew Birkin, Bernd Eichinger e Martin Moszkowicz. Roteiro: Patrick Süskind (livro), Andrew Birkin e Bernd Eichinger. [S. 1.: s. n.], 2006. Disponível em:

https://www.youtube.com/watch?v=6ecdP6tce_8. Acesso em: 19 out. 2019.

PINHEIRO, Nilcéia Aparecida Maciel. Educação crítico-reflexiva para um ensino médio científico-tecnológico: a contribuição do enfoque CTS para o ensino-aprendizagem do conhecimento matemático. 2005. 306 f. Tese (Doutorado em Educação Científica e Tecnológica) - Universidade Federal de Santa Catarina, Florianópolis, 2005.

PISTARINI, Nara Flaviane; MILARÉ, Tathiane. Ensino de Química em Oficina Temática: O que vai pelo ralo: rastros ambientais de produtos que consumimos. Revista Debates em Ensino de Química. v. 5, n. 1, p. 32 - 41, 2019.

POLÔNIO, Maria Lúcia Teixeira; PERES, Frederico. Consumo de aditivos alimentares e efeitos à saúde: desafios para a saúde pública brasileira. Caderno de Saúde Pública, Rio de Janeiro, v. 25, n. 8, p. 1653-1666, 2009. 
REIS, André Silva dos; SILVA, Maria Dulcimar de Brito; BUZA, Ruth Gabriel Canga. O uso da história da ciência como estratégia metodológica para a aprendizagem do ensino de química e biologia na visão dos professores do ensino médio. História da Ciência e Ensino: Construindo Interfaces, v. 5, p. 1-12, 2012. Disponível em:

https://revistas.pucsp.br/hcensino/article/view/9193/7340. Acesso em: 14 out. 2019.

SANTOS, Wildson Luiz Pereira dos; MORTIMER, Eduardo Fleury. Uma análise de pressupostos teóricos da abordagem C-T-S (Ciência - Tecnologia - Sociedade) no contexto da educação brasileira. Ensaio: Pesquisa em Educação em Ciências, Belo Horizonte, v. 2, n. 2, p. 110-132, 2000.

SANTOS, Wildson Luiz Pereira dos; MORTIMER, Eduardo Fleury. Abordagem de aspectos sociocientíficos em aulas de ciências: possibilidades e limitações. Investigações em Ensino de Ciências, v. 14, n. 2, p. 191-218, 2009.

SANTOS, Wildson Luiz Pereira. Aspectos sociocientíficos em aulas de química. 2002. 338 f. Tese de doutorado (Doutorado em Educação) - Universidade Federal de Minas Gerais, Faculdade de Educação, Belo Horizonte, 2002.

SANTOS, Wildson Luiz Pereira; SCHNETZLER, Roseli Pacheco. Educação em química: Compromisso com a cidadania. 4. ed. rev. e atual. Ijuí: Unijuí, 2010. 160 p.

SILVA, Giovanna Stefanello et al. Oficina temática: uma proposta metodológica para o ensino do modelo atômico de Bohr. Ciência e Educação. Bauru, v. 20, n. 2, p. 481-495, 2014.

SOUZA, Fabio de et al. Oficinas Temáticas visando à Divulgação Científica em aulas de Química. In: SIMPÓSIO SOBRE DIVULGAÇÃO CIENTÍFICA NA SALA DE AULA: PERSPECTIVAS E POSSIBILIDADES, 2014, São Paulo, 2014. Anais [...]. São Paulo: USP, 2014, p. 57- 59. Disponível em:

http://www.lapeq.fe.usp.br/eventos/simposio_dc/caderno_resumos.pdf. Acesso em: 29 mar. 2020.

TEIXEIRA, Paulo Marcelo Marini. Educação científica e movimento CTS no quadro das tendências pedagógicas no Brasil. Revista Brasileira de Pesquisa em Educação em Ciências, v. 3, ed. 1, p. 88-102, 2011.

TOWSE, Peter J. Editorial. International Newsletter on Chemical Education-IUPAC, n. 26, p. 2-3, 1986.

YAGER, Robert E.; McCORMACK, Alan J. Assessing teaching/learning successes in multiple domains of science and science education. Science Education, v. 73, n.1, p. 45-48, 1989.

Recebido em março de 2020.

Aprovado em maio de 2020. 